\title{
Mystery US outbreak prompts further tests
}

\section{Tourette's-like disorder in New York school confounds experts.}

\section{Alison Motluk}

20 February 2012

Last week, officials with the LeRoy Central School District in northwestern New York state approved a plan for further environmental testing at the town's high school, where 19 people - 18 girls and one boy — have developed a sudden-onset disorder with symptoms similar to the movement disorder Tourette's syndrome. The outbreak has captured national attention and led experts to suggest an array of possible explanations - none of which seem to quite work. With speculation running high, here is a look at the facts surrounding the outbreak.

\section{How and when did the symptoms appear?}

Several of the girls report that the symptoms seemed to come out of nowhere - one minute they were asleep, the next they had woken and developed uncontrollable movements and vocalizations. Their tics could be dramatic: arms twitching or jolting out to one side, speech chopped up by nonsense utterings, head jerking, eyes blinking. Some girls have also had blackouts and seizures. The first case was in May last year, the second in early September. By the end of October, eight students were affected. That is when the New York State Department of Health was called in to investigate.

\section{Is there some contaminant in the school?}

If there is, no one has found it yet. The high school was built in 2003 and has about 630 students. School officials commissioned airquality testing in late December, measuring levels of 58 volatile organic chemicals, 63 pesticides and herbicides, 11 metals, cyanide, polychlorinated biphenyls and ketones. They found nothing amiss. They also found no evidence of fungus or mould and no problems with ventilation. Water was tested at two locations inside the school as well as at the point where the municipal supply enters the school, and the water quality seems fine.

\section{What do the students' doctors think?}

Eight of the girls have been diagnosed with 'conversion disorder', or mass hysteria. (Three of the girls had reported prior tic problems.) Cases of conversion disorder generally occur among people who are in close contact with each other. Usually there is a trigger, such as a smell, and then one person becomes ill, followed by many others. The sickness seems to be organic, but investigations identify no physical cause. Females are affected more often than males. In such cases, the symptoms are distinct: for instance seizures occur without characteristic changes in an electroencephalogram. The condition is rare, but the health department's report cites a few other cases in the medical literature. One describes a Tennessee high school at which the smell of gas, with no evidence of an actual gas leak, led to dozens of reports of illness. But the LeRoy situation doesn't fit the diagnosis very well, say sceptics. The cases emerged over many months, and the students ranged in age from 13 to 19 years and were in five different grades. They did not spend time with each other and, at first, were not aware of each other's symptoms.

\section{Could it be an infection?}

There is growing awareness that a bacterial infection can lead to sudden-onset tics. Known as PANDAS, or PANS, the syndrome is thought to be an autoimmune disorder. Again, however, these students' cases don't quite fit. None reported a serious infection immediately before the symptoms set in, they are older than is typical for the disorder, and PANS usually affects boys more than girls and doesn't usually present in clusters. There is no definitive test for the condition, but to the extent that blood can hint at past infections, only some of the girls have evidence of recent bacterial infection.

\section{What about environmental toxins?}

This is a question that continues to haunt locals, because in December 1970, LeRoy was the site of a train derailment that spilt one tonne of what the Environmental Protection Agency describes as "cyanide crystals" and more than 114,000 litres of the industrial solvent trichloroethene (TCE). The spill site is about 5.6 kilometres from the school and, although there is groundwater contamination, 
it is well monitored and does not extend to the school area. Gravel from a quarry near the spill site was used to construct a playing field at the school. But water in the school was specifically tested for traces of TCE and levels were not elevated. Also, although TCE exposure has been linked to many conditions — for example, nausea, liver damage and cancer — tics are not among them. The only possible link is that it may increase the risk of another movement disorder, Parkinson's disease.

\section{Could the human papillomavirus vaccine be involved?}

Only seven of the girls had received the vaccine and, in each case, more than a year had elapsed between the last dose and the onset of symptoms. Tics are not a known side effect of the vaccine (Gardasil).

\section{What happens next?}

Some of those affected have now recovered. School officials have approved further testing of both the air and the soil, but still insist that there is no danger to other students.

Nature | doi:10.1038/nature.2012.10052 